\title{
Análise de um Sistema de Refrigeração de uma Prensa Hidráulica no Setor Cerâmico
}

\section{Analysis of a Cooling System of a Press Hydraulic \\ Ceramic Industry}

\author{
Geovane Rosso Felipe \\ Faculdade SATC, Criciúma, SC \\ geovanerf@botmail.com \\ Aline Resmini Melo \\ Faculdade SATC, Criciúma, SC \\ alinermelo@yahoo.com.br \\ Carolina Resmini Melo \\ Faculdade SATC, Criciúma, SC \\ resmini1@yahoo.com.br
}

Resumo: Uma empresa, do ramo cerâmico, situada em Santa Catarina, deparou-se com a necessidade de aumentar sua produção mensal. Com esse objetivo, os ciclos por minuto de suas prensas hidráulicas foram aumentados, gerando paradas no processo produtivo, devido ao sistema de refrigeração do óleo, utilizado, ser ineficaz para este novo número de ciclos. Para solucionar o problema, a empresa optou pela utilização de um segundo trocador de calor no sistema de refrigeração. Assim, a transferência de calor aumentou, e a temperatura do fluido foi reduzida dando continuidade ao processo. Com a chegada do verão, quando a temperatura externa sobe consideravelmente, as paradas no processo produtivo voltaram a ocorrer. Com o intuito de resolver o problema de troca térmica, foram feitas análises térmicas, levando em consideração tanto a eficácia do processo como a viabilidade econômica. Com base nos valores encontrados, foram propostos dois novos casos a serem estudados para resolver o problema. Sendo a solução o uso de um novo trocador de calor, com uma área de troca térmica que atende à necessidade de troca térmica exigida pelo processo.

Recebido em 18/09/2011 - Aceito em 25/07/2012.

\begin{tabular}{|c|c|c|c|c|c|}
\hline RECEN & 14(1) & p. $59-77$ & jan/jun & 2012 & DOI: $10.5777 /$ RECEN.2012.01.04 \\
\hline
\end{tabular}


Palavras-chave: prensa hidráulica; processo cerâmico; trocador de calor casco e tubos.

\begin{abstract}
A company, in the ceramic industry, located in Santa Catarina, was faced with the need to increase its monthly production. With this objective, the cycles per minute of their hydraulic presses were increased, resulting in the production process stops, due to the cooling system of the oil used to be ineffective for this new number of cycles. In order to solve the problem, the company opted for the use of a second heat exchanger in the cooling system. Thus, the heat transference increased and fluid temperature decreased continuing the process. With the arrival of summer, when the outside temperature rises considerably, the stakes in the production process reoccurred. In order to solve the problem of heat thermal transferences analyzes were conducted, taking into account both process efficiency and economic viability. Based on the values found, we proposed two new cases to be studied to solve the problem. The solution found was the use of a new heat exchanger with a heat transference area that meets the need of heat exchange required for the process.
\end{abstract}

Key words: ceramic process; hydraulic press; shell and tubes heat exchanger.

\title{
1 Introdução
}

Estima-se que 1\% do PIB (Produto Interno Bruto) do Brasil está diretamente ligado à cerâmica industrial que tem um papel importante para a economia do país. Atualmente, o Brasil vem se destacando mundialmente, ocupando o quarto lugar em produção, ficando atrás apenas da China, Itália e Espanha. A maior parte das indústrias brasileiras de cerâmicas para revestimentos encontram-se no estado de Santa Catarina, que é o maior produtor do país.

Os processos mais importantes em uma cerâmica industrial são a moagem, atomização e o processo de prensagem. Neste último, através de prensas hidráulicas, a peça ganha a geometria e resistência a cru, possibilitando a continuidade do processo. 
As prensas hidráulicas funcionam através da circulação de um fluido em todo o sistema hidráulico. Em consequência da turbulência e do atrito na tubulação, ocorre um aumento considerável na temperatura do fluido. Esse aumento altera suas características, como, por exemplo, a viscosidade, que é reduzida.

As prensas hidráulicas trabalham continuamente sendo necessária a utilização de um sistema para refrigeração do fluido hidráulico. Esse trocador, do tipo casco e tubos, tem como finalidade manter a temperatura do fluido hidráulico com o objetivo de garantir suas características físico-químicas.

Com o crescimento da produção no setor cerâmico, uma indústria da região de Criciúma aumentou os ciclos por minuto das suas prensas, o que gerou paradas no processo produtivo, em função de o sistema de refrigeração utilizado não ser eficaz para este novo número de ciclos.

A fim de solucionar o problema, foi colocado um segundo trocador de calor no sistema de refrigeração. Assim, a transferência de calor aumentou, e a temperatura do fluido foi reduzida dando continuidade ao processo. Com a chegada do verão tempo em que a temperatura externa sobe consideravelmente, o processo voltou a parar.

Para resolver o problema de troca térmica, foi feita análise da viabilidade da alteração de parâmetros com a utilização de dois trocadores de calor nesse sistema de refrigeração da prensa hidráulica, levando em consideração tanto a eficácia do processo como a viabilidade econômica.

Analisando todos os fatores envolvidos, foi sugerida uma alteração, garantindo a possibilidade de a empresa estabelecer um processo contínuo que garanta a produção orçada e seja economicamente viável.

Devido à alta produtividade, a prensagem é o processo de conformação mais usado para fabricação de peças cerâmicas. O princípio da lei de Pascal está presente na prensa hidráulica [1]. A lei de Pascal enuncia-se da seguinte forma: "Em qualquer ponto no interior de um líquido em repouso, a pressão é mesma em todas as direções".

As prensas hidráulicas utilizam um fluido para aplicar pressão a um cilindro; esse, por sua vez, consegue exercer uma pressão com seus movimentos, velocidade e carga, ajustados por meio de um sistema de controle adequado. As prensas hidráulicas têm sua limitação de potência e velocidade em função do sistema hidráulico empregado 
[2].

As prensas hidráulicas utilizadas nas indústrias cerâmicas têm um sistema hidráulico composto por um reservatório de óleo que, normalmente, é encontrado no interior da estrutura da prensa, uma bomba de pistão acionada por motor elétrico, um trocador de calor e um multiplicador de pressão que aumenta a pressão na região do sistema que transmite ao punção superior [3]. Esse sistema hidráulico é capaz de bombear óleo necessário para efetuar o ciclo de prensagem.

Com o processo em série e as prensas trabalhando continuamente, os fluidos hidráulicos acabam sofrendo, por consequência da turbulência e do atrito na tubulação e nas válvulas, aumento considerável na temperatura, o que acaba exigindo um sistema de refrigeração como a utilização de um trocador de calor.

O trocador de calor faz o processo de troca de calor entre dois fluidos que estão em temperaturas diferentes. Esse equipamento é utilizado em muitas aplicações na engenharia como no aquecimento de ambientes e no condicionamento de ar, na produção de potência, na recuperação de calor e no processamento químico, entre outros [2].

Os trocadores de calor são normalmente classificados de acordo com o arranjo do escoamento e o tipo de construção. Existem três tipos básicos de trocador de calor de acordo com o tipo de construção [4]. Nos do tipo recuperador, os fluidos de temperaturas distintas são separados por uma parede, e o calor acaba sendo transferido por convecção e condução. Nos do tipo regenerador, os fluidos de diferentes temperaturas ocupam alternadamente o mesmo espaço no núcleo do trocador. E um terceiro tipo, os de contato direto, que como o próprio nome já diz, os fluidos quente e frio entram em contato direto. A classificação, de acordo com o arranjo do escoamento dos fluidos, é a seguinte [5]: correntes paralelas, contrárias ou cruzadas.

O trocador de calor casco e tubos (recuperador) é o tipo mais comum nas indústrias. Nesse trocador, um fluido se desloca por dentro dos tubos, enquanto um segundo fluido é forçado a passar ao longo do envoltório da superfície dos tubos. $\mathrm{O}$ escoamento dos fluidos pode ser em correntes paralelas ou contrárias.

Segundo Rosa [6], podem-se destacar como principais componentes deste trocador o feixe de tubos, o cabeçote de entrada e o cabeçote de retorno. O feixe tubular 
é formado por uma série de tubos fixados por suas pontas em espelhos. Esses trocadores ainda podem contar com a instalação de chicanas, o que aumenta o coeficiente convectivo do fluido no lado do casco. Isso ocorre pela indução de uma turbulência no escoamento, acarretando um aumento da taxa de transferência de calor. As chicanas também proporcionam apoio físico aos tubos, reduzindo a vibração, que é induzida pelo escoamento. O casco é composto de um cilindro, com suas extremidades soldadas aos flanges ou aos próprios espelhos, dependendo do tipo de construção.

\section{Equacionamento}

Atualmente, o trocador de calor utilizado, no caso estudado, é do tipo casco e tubo com dois passes no casco e quatro passes nos tubos. A figura 1 mostra um esquema do fluxo do fluido ao longo do trocador de calor.

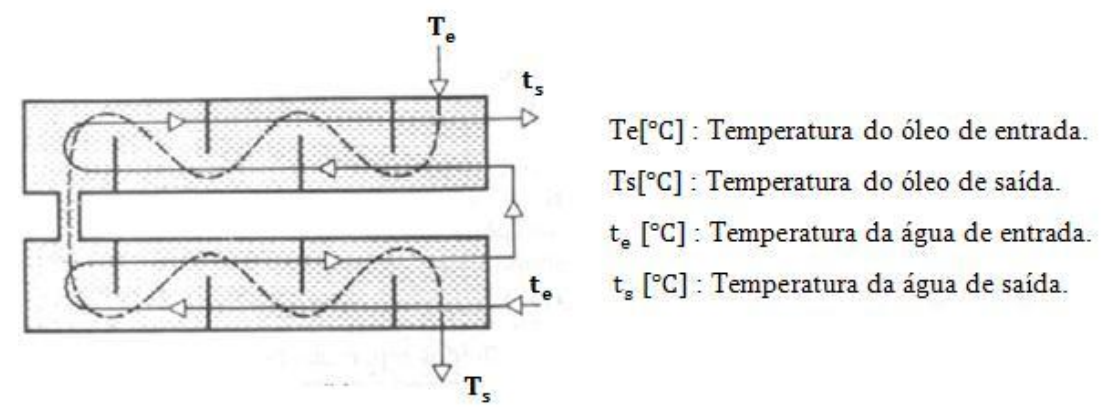

Figura 1. Trocador de calor (caso atual) [5]

Para prever a taxa de transferência de calor “q" [W] de um trocador de calor, a equação (1) pode ser aplicada [4].

$$
\dot{q}=\dot{m} \times C p \times \Delta T
$$

Em que $\dot{m}[\mathrm{~kg} / \mathrm{s}]$ é o fluxo de massa do fluido; Cp $[\mathrm{J} / \mathrm{kg} . \mathrm{K}]$ é o calor específico e $\Delta T$ é a variação de temperatura.

O valor do calor específico, assim como de outras propriedades termofísicas necessárias para os cálculos, foram obtidos através da média aritmética dada por:

$$
\frac{t_{e}-t_{s}}{2}
$$


Em que $t_{e}\left[{ }^{\circ} \mathrm{C}\right]$ é a temperatura da água que entra no trocador de calor e $t_{s}\left[{ }^{\circ} \mathrm{C}\right]$ a temperatura da água que sai do trocador de calor.

A partir da equação(1), tem-se:

$$
\dot{q}_{a t u a l}=\dot{m}_{a g u a} \times C p_{a g u a} \times \Delta T_{a g u a}
$$

Para, posteriormente, ser feito o cálculo da taxa de transferência de calor para o caso antigo (onde havia somente um trocador de calor), é necessário conhecer a vazão do óleo, que pode ser encontrada através de um balanço de energia, em que a taxa de transferência de calor trocada pela água é a mesma taxa de transferência trocada pelo óleo; assim tem-se:

$$
\dot{m}_{a g u a} \times C p_{a g u a} \times \Delta T_{a g u a}=\dot{m}_{\text {oleo }} \times C p_{\text {oleo }} \times \Delta T_{\text {oleo }}
$$

Para encontrar o coeficiente global de transferência de calor, é possível relacionálo com a taxa total de transferência de calor e grandezas, tais como as temperaturas de entrada e saída do fluido, e a área total de transferência de calor [4]:

$$
q_{\text {atual }}=U \times A \times \Delta T_{l m}
$$

Em que $\mathrm{U}\left[\mathrm{W} / \mathrm{m}^{2} . \mathrm{K}\right]$ é o coeficiente global de transferência de calor; A $\left[m^{2}\right]$ é a área total de transferência de calor e $\Delta T_{l m}[\mathrm{~K}]$ é a média logarítmica da diferença de temperatura.

Conforme Balbueno [7], em um trocador real, as temperaturas dos fluidos quente e frio variam de ponto a ponto à medida que o calor é transferido ao longo do trocador de calor. É necessário estabelecer uma diferença de temperatura apropriada, utilizando o método de média logarítmica das diferenças de temperatura , conforme a equação (6). Como os fluxos não são puramente contracorrente ou puramente cocorrente, e sim uma combinação dos dois, agrega-se um fator de correção $\mathrm{F}$, no qual é utilizada equação (7). A diferença média de temperatura pode ser vista nas equações (6) e (7), considerando-se as seguintes hipóteses:

1. A transferência de calor ocorre em estado estacionário. 
2. Os calores específicos de cada corrente são constantes.

3. O coeficiente global de tranferência de calor U é constante ao longo do trocador.

4. As perdas ou ganhos de calor para as vizinhanças são negligenciáveis.

5. Não existe mudança de fase no trocador de calor.

$$
\begin{gathered}
\Delta T_{l m 1}=\frac{\Delta T_{1}-\Delta T_{2}}{\ln \frac{\Delta T_{1}}{\Delta T_{2}}} \\
\Delta T_{l m}=F \times \Delta T_{l m 1} C F
\end{gathered}
$$

Em que $\Delta T_{l m 1} C F$ é a média logarítmica das diferenças de temperatura, $\Delta T_{1} \mathrm{e}$ $\Delta T_{2}$ são, respectivamente, a diferença de temperatura dos fluidos quentes e frios e $\mathrm{F}$ é um fator de correção adimensional.

A média logarítmica da diferença de temperatura é obtida pelas temperaturas já fornecidas, onde $\Delta T_{1}$ e $\Delta T_{2}$ são apresentados através das equações [8] e 9 .

$$
\Delta T_{1}=T_{e}-t_{s}
$$

Em que $T_{e}[\mathrm{~K}]$ é a temperatura de entrada do fluido quente no trocador e $t_{s}[\mathrm{~K}]$ é a temperatura de saída do fluido quente no trocador.

$$
\Delta T_{2}=T_{s}-t_{e}
$$

Em que $T_{s}[\mathrm{~K}]$ é a temperatura de saída do fluido quente no trocador e $t_{e}[\mathrm{~K}]$ é a temperatura de entrada do fluido quente no trocador.

Segundo Welty et. al [8], o fator de correção F para um trocador de casco e tubo, pode ser obtido através de um gráfico apresentado em Bowman [9]. Outra forma de calcular o fator de correção $\mathrm{F}$ para um número de $\mathrm{N}$ passes no casco é representada por [9]: 


$$
F=\frac{\sqrt{R^{2}+1} \times \ln \left(\frac{1-P_{0} \times R}{1-P_{0}}\right)}{(1-R) \times \ln \left(\frac{2-P_{0} \times\left(R+1-\sqrt{R^{2}+1}\right)}{2-P_{0} \times\left(R+1+\sqrt{R^{2}+1}\right)}\right)}
$$

Em que $P$, dado pela equação (11), é um indicativo do rendimento térmico (adimensional) e R, dado pela equação (12), representa a razão entre os produtos da vazão mássica e o calor específico dos dois fluidos (adimensional).

$$
\begin{aligned}
& P=\frac{t_{s}-t_{e}}{T_{e}-t_{e}} \\
& R=\frac{T_{e}-t_{e}}{t_{s}-t_{e}}
\end{aligned}
$$

O parâmetro $P_{0}$, a ser utilizado, será corrigido, quando tiver dois cascos, por:

$$
P_{0}=\frac{\left(\frac{1-P \times R}{1-P}\right) \times \frac{1}{N-1}}{\left(\frac{1-P \times R}{1-P}\right) \times \frac{1}{N-R}}
$$

Em que $\mathrm{N}$ é o número de passos no casco.

O número de Reynolds crítico $R e_{D}$ correspondente ao surgimento da turbulência é de, aproximadamente, 2300 e pode ser obtido pela equação (14) [5]. Em todos os casos estudados neste trabalho, o escoamento do fluido frio encontrado é turbulento.

$$
R e_{D}=\frac{4 \times \dot{m}_{a g u a}}{\pi \times D_{t u b o s} \times \mu}
$$

Em que $D_{\text {tubos }}[\mathrm{m}]$ é o diâmetro interno dos tubos e $\mu\left[N . s / \mathrm{m}^{2}\right]$ é a viscosidade da água.

Para resfriamento que são os casos estudados, o número de $\mathrm{Nusselt}, \mathrm{Nu}_{D}$, é dado por [5]:

$$
N u_{D}=0,0265 \times \operatorname{Re}_{D 5}{ }^{4} \times \operatorname{Pr}^{0,3}
$$

Em que $\operatorname{Pr}=C p \times \mu / k$ é adimensional e chamado de número de Prandtl.

$\mathrm{O}$ coeficiente de convecção interno $\mathrm{h}_{i},\left[\mathrm{~W} / \mathrm{m}^{2} \mathrm{~K}\right]$, é obtido por [6]:

$$
h_{i}=N u_{D} \times \frac{K}{D}
$$


sendo $\mathrm{D}[\mathrm{m}]$ o diâmetro dos tubos e $\mathrm{K}[\mathrm{W} / \mathrm{m} . \mathrm{K}]$ a condutividade térmica. A área $\mathrm{A}$ $[\mathrm{m}]$ pode ser obtida por:

$$
A=N_{\text {tubos }} \times 2 \times L_{\text {tubos }} \times \pi \times D_{\text {tubos }} \times N_{c}
$$

Em que $N_{\text {tubos }}$ é o número de tubos; $L_{\text {tubos }}[\mathrm{m}]$ é o comprimento dos tubos no trocador e $N_{c}$ o número de passes no casco.

O coeficiente de convecção externo pode ser encontrado por [5]:

$$
U=\frac{1}{\frac{1}{h_{i}}+\frac{1}{h_{e}}}
$$

Em que $\mathrm{h}_{e}\left[\mathrm{~W} / m^{2} . \mathrm{K}\right]$ é o coeficiente de convecção externo.

Antes da utilização de um segundo trocador de calor no sistema de refrigeração, estava sendo utilizado apenas um trocador de calor do tipo casco e tubo com um passe no casco e dois passes nos tubos. A figura 2 mostra um esquema dos fluxos dos fluidos ao longo do trocador de calor.

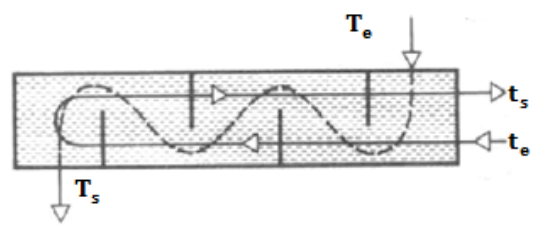

Figura 2. Trocador de calor (caso antigo) [5]

O desempenho do trocador de calor antigo pode ser obtido pela aplicação do balanço global de energia para o fluido. A partir da equação (1), tem-se :

$$
\dot{q}_{\text {antigo }}=\dot{m}_{\text {oleo }} \times \dot{C}_{\text {oleo }} \times \Delta T_{\text {oleo }}
$$

Para saber a melhoria proporcionada por essa opção, é só comparar os dois casos, utilizando a equação 20. Encontrando o valor da porcentagem melhorada com a utilização de um segundo trocador de calor usa-se:

$$
P_{\text {melhorada }}=\left(100 \times \frac{q_{\text {atual }}}{q_{\text {antigo }}}\right)-100
$$

Em que $\mathrm{q}_{\text {atual }}[\mathrm{W}]$ é a troca térmica de transferência de calor atual e $q_{\text {antigo }}[\mathrm{W}]$ 
é a taxa antiga de transferência de calor.

Para calcular uma nova taxa de transferência de calor com uma porcentagem de melhoria em relação ao caso antigo, pode-se aplicar:

$$
\dot{q}_{\text {ideal }}=\frac{\dot{q}_{\text {antigo }} \times(P T+100)}{100}
$$

Em que PT é a porcentagem que se pretende melhorar na taxa de transferência de calor e $\dot{q}_{i d e a l}$ é a taxa de transferência ideal para o sistema de refrigeração.

O cálculo para encontrar o custo da parada de uma prensa para limpeza no trocador de calor Custo daparada é dado por:

$$
\text { Custo }_{\text {daparada }}=P_{m} \times T \times A_{\text {formato }} \times C
$$

Em que $P_{m}[R \$]$ é o preço por metro quadrado do piso; T [min] é o tempo que a prensa ficou parada; $A_{\text {Formato }}\left[\mathrm{m}^{2}\right]$ é a área do formato do piso que a prensa estava batendo e $\mathrm{C}$ [ciclo/min] é a quantidade de peças que a prensa bate em um minuto.

A equação 23. apresenta o cálculo de consumo de energia (C usto energia $_{\text {) para }}$ um equipamento com a potência conhecida.

$$
\text { Custo }_{\text {energia }}=P k w \times \frac{P \times t}{1000}
$$

Em que $\mathrm{Pkw}$ é o preço por $\mathrm{kW} / \mathrm{h}$ que a empresa paga na conta de energia; $\mathrm{t}$ [s] é o tempo em que o equipamento permanece ligado e $\mathrm{P}$ [W] a potência do aparelho.

\section{Resultados e análises}

Para calcular a taxa de transferência de calor do caso atual, foi utilizada a equação (3), onde a vazão fornecida pela bomba centrífuga que alimenta oito prensas, ou seja, oito trocadores a dois bar de pressão em um sistema aberto, é de 35.000 1/h. Dividindo a vazão total por oito e convertendo para o sistema internacional de unidade de medida, tem-se que o fluxo de massa para o trocador estudado é de $1,2 \mathrm{~kg} / \mathrm{s}$.

A temperatura de entrada do trocador foi medida no reservatório do fluido frio com um termômetro digital que mostrou uma temperatura média de $24^{\circ} \mathrm{C}$. Em re- 
lação à temperatura de saída do trocador de calor a qual foi medida no fluido que passa por um registro logo após a saída do trocador de calor, o termômetro digital apresentou uma temperatura média de $31^{\circ} \mathrm{C}$. Para o calor específico, é utilizada uma média aritmética conforme a equação (2), resultando aproximadamente $300 \mathrm{~K}$. Nessa temperatura, o valor do calor específico da água é de aproximadamente $4179 \mathrm{~J} / \mathrm{kg} . \mathrm{K}$, conforme a tabela de propriedades termofísicas da água, encontrada em Incropera [5]. Assim, resolvendo a equação (3), tem-se que a taxa de transferência de calor atual é de $35,1 \mathrm{~kW}$.

Do mesmo modo foi avaliado o caso antigo: a temperatura de entrada do trocador é de $24^{\circ} \mathrm{C}$, a de saída do trocador é de $30^{\circ} \mathrm{C}$ e a taxa de transferência de calor do caso antigo é de $30,1 \mathrm{~kW}$.

O calor específico do óleo ATF 200, que é o utilizado na prensa estudada, foi fornecido pelo suporte técnico da empresa responsável pelo fornecimento do óleo sendo de $1.963,66 \mathrm{~J} / \mathrm{kg}$. K. A temperatura de saída do óleo foi medida com um termômetro digital infravermelho, mostrando em seu visor uma temperatura média de $37^{\circ} \mathrm{C}$; a temperatura de entrada é fornecida por um termômetro digital que se encontra no próprio painel da prensa, para monitoração dos operadores e apresentou uma temperatura média de $56^{\circ} \mathrm{C}$. Foram somadas as duas temperaturas e o resultado dividido por dois e, posteriormente, interpolado para dar um valor mais exato. Resolvendo a equação (4), é encontrada a vazão do óleo de $0,94 \mathrm{~kg} / \mathrm{s}$.

A temperatura média de entrada do óleo (no caso antigo) era de $65^{\circ} \mathrm{C}$, assim, a temperatura de saída pode ser calculada utilizando a equação 19 . Como o calor específico do óleo varia conforme a temperatura, o $C p_{\text {oleo }}$ foi definido inicialmente para $50^{\circ} \mathrm{C}$. Resolvendo a equação [19], é encontrada uma temperatura; se for diferente da definida inicialmente, é recalculado com a nova temperatura até o $C p_{o l e o}$, coincidir com a temperatura calculada. Isso ocorreu com a temperatura de saída, aproximadamente $49^{\circ} \mathrm{C}$, quando a temperatura média se encontra com aproximadamente $57^{\circ} \mathrm{C}$ e com $C p_{\text {oleo }}$ de $2.012,47 \mathrm{~J} / \mathrm{kg}$. K.

Para saber a melhoria proporcionada pela utilização de um segundo trocador de calor colocado em série, basta comparar os dois casos através da equação 20. A escolha por esta opção melhorou em $16,6 \%$ a transferência de calor no sistema de 
refrigeração.

A tabela 1 apresenta os resultados intermediários para o cálculo do coeficiente global de transferência de calor, tanto para o caso antigo como para o atual.

A área total de troca térmica pode ser calculada através da equação (17), onde o comprimento, a quantidade e os diâmetros dos tubos foram medidos na própria empresa. Para o caso atual a área total de troca térmica é de $12,18 \mathrm{~m}^{2}$, o caso antigo tinha uma área de troca térmica de $6,09 \mathrm{~m}^{2}$. Com os valores encontrados, é possível encontrar o coeficiente global de convecção para os dois casos, aplicando a equação (5).

Para calcular o coeficiente de convecção interno, foi utilizada uma média aritmética conforme a equação (2). O resultado foi de aproximadamente $300^{\circ} \mathrm{K}$, para os dois casos, sendo que as propriedades termofísicas da água com as variações conforme as temperaturas são: $C p_{a g u a}=4179 \mathrm{~J} / \mathrm{kg} .{ }^{\circ} \mathrm{K} ; \mu=855 \times 10^{-6} N . s / \mathrm{m}^{2} ; \mathrm{K}=$ $0,613 \mathrm{~W} / \mathrm{m} .{ }^{\circ} \mathrm{K} ; \operatorname{Pr}=5,83$.

A seguir, serão apresentados casos propostos para resolver o problema da troca térmica neste sistema de refrigeração, com o aumento da vazão da água ou utilização de um trocador de calor novo, cuja área total de troca térmica suprisse a necessidade do sistema.

Para calcular a taxa de transferência de calor com um novo trocador de calor, foi adotada uma transferência de calor de 33,34\% maior que o caso antigo, ou seja, o dobro do caso atual. Através de equação (21), foi calculada a nova taxa de transferência de calor, que resultou em uma taxa de transferência de calor de 40,1 kW.

A temperatura de entrada ideal do óleo no trocador de calor não deve ultrapassar a $53{ }^{\circ} \mathrm{C}$ e a temperatura de saída de $31,1^{\circ} \mathrm{C}$. A temperatura de saída da água pode ser calculada através da equação (3), encontrando-se o valor de $32^{\circ} \mathrm{C}$.

A temperatura de entrada da água é a mesma para todos os casos, sendo de $24^{\circ} \mathrm{C}$; a temperatura de saída pode ser calculada pela equação (3), encontrando-se $32^{\circ} \mathrm{C}$.

Calculado o $\Delta T_{l m}$, mostrado na tabela 2, e definindo um coeficiente global de $330 \mathrm{~W} / m^{2} \mathrm{~K}$, é possível, através da equação (5), encontrar a área para que o sistema de refrigeração trabalhe com os dados apresentados acima, sendo necessária uma área total de troca térmica de $12,38 \mathrm{~m}^{2}$. 
Tabela 1. Resultados dos parâmetros para o cálculo do coeficiente global de transferência de calor

\begin{tabular}{lccc}
\hline Parâmetros & Caso Atual & Caso Antigo & $N^{\circ}$ da equação \\
\hline $\mathrm{R}[-]$ & 2,17 & 2,67 & 12 \\
$\mathrm{P}[-]$ & 0,22 & 0,15 & 11 \\
$P_{0}[-]$ & 0,14 & - & 13 \\
$\Delta t_{1}\left[{ }^{\circ} \mathrm{C}\right]$ & 25 & 35 & 8 \\
$\Delta t_{2}\left[{ }^{\circ} \mathrm{C}\right]$ & 13 & 25 & 9 \\
$\Delta t_{l m 1}\left[{ }^{\circ} \mathrm{C}\right]$ & 18,35 & 29,72 & 6 \\
$\Delta t_{l m}\left[{ }^{\circ} \mathrm{C}\right]$ & 18,04 & 29,17 & 7 \\
$\mathrm{~F}[-]$ & 0,98 & 0,98 & 10 \\
$R e_{D}[-]$ & 119133,63 & 119133,63 & 14 \\
$N u_{D}[-]$ & 517,34 & 517,34 & 15 \\
$h_{i}\left[\mathrm{~W} / m^{2} \cdot \mathrm{K}\right]$ & 21141,86 & 21141,86 & 16 \\
$\mathrm{U}\left[\mathrm{W} / m^{2} \cdot \mathrm{K}\right]$ & 159,78 & 169,42 & 5 \\
$h_{e}\left[\mathrm{~W} / m^{2} \cdot \mathrm{K}\right]$ & 160,99 & 170,79 & 18 \\
\hline
\end{tabular}

O catálogo de informações técnicas [10] apresenta uma série de trocadores de calor do tipo casco e tubo, com um passe no casco e dois nos tubos. O trocador 8-2000 é o trocador que tem a área total de troca térmica mais próxima da calculada.

Recalculado para essa nova área encontrada, tem-se um novo coeficiente global de convecção de $317 \mathrm{~W} / m^{2} \mathrm{~K}$.

Outro caso proposto estudado foi o aumento da vazão com os dois trocadores já existentes, garantindo a temperatura ideal do óleo para a prensa hidráulica.

Para calcular as taxas de transferência de calor para os dois casos anteriores foi adotada uma transferência de calor de 33,34\% maior que o caso antigo, ou seja, o dobro do caso atual. Através de equação 21, foi calculada a nova taxa de transferência de calor com um aumento de 33,34\%, que resultou em uma taxa de transferência de calor de 40.120,41 W. A vazão definida foi a mesma, $1,92 \mathrm{~kg} / \mathrm{s}$.

A temperatura ideal de entrada do óleo no trocador de calor não deve ultrapassar $53^{\circ} \mathrm{C}$, sendo recomendável que a temperatura de saída seja de $31,1^{\circ} \mathrm{C}$. A temperatura de saída da água pode ser calculada através da equação (3), encontrando-se o valor de $29^{\circ} \mathrm{C}$. A área total de troca térmica é a mesma para o caso atual, já que será utilizado o mesmo trocador de calor.

A tabela 2 apresenta os resultados intermediários e o final do coeficiente global 
de transferência de calor para os casos propostos.

Tabela 2. Resultados dos parâmetros para o cálculo do coeficiente global de transferência de calor

\begin{tabular}{lccc}
\hline Parâmetros & $\begin{array}{c}\text { Caso proposto utilizando } \\
\text { um novo trocador de calor }\end{array}$ & $\begin{array}{c}\text { Caso proposto para o caso atual } \\
\text { com um aumento da vazão }\end{array}$ & $\begin{array}{c}N^{\circ} \mathrm{da} \\
\text { equação }\end{array}$ \\
\hline $\mathrm{R}[-]$ & 2,74 & 4,38 & 12 \\
$\mathrm{P}[-]$ & 0,28 & 0,17 & 11 \\
$P_{0}[-]$ & - & 0,12 & 13 \\
$\Delta t_{1}\left[{ }^{\circ} \mathrm{C}\right]$ & 21 & 24 & 8 \\
$\Delta t_{2}\left[{ }^{\circ} \mathrm{C}\right]$ & 7,1 & 7,1 & 9 \\
$\Delta t_{l m 1}\left[{ }^{\circ} \mathrm{C}\right]$ & 12,82 & 13,88 & 6 \\
$\Delta t_{l m 2}\left[{ }^{\circ} \mathrm{C}\right]$ & 9,82 & 13,88 & 7 \\
$\mathrm{~F}[-]$ & 0,77 & 0,98 & 10 \\
$R e_{D}[-]$ & 119133,63 & 190613,8 & 14 \\
$N u_{D}[-]$ & 517,34 & 753,48 & 15 \\
$h_{i}\left[\mathrm{~W} / m^{2} \cdot \mathrm{K}\right]$ & 21141,86 & 30792,09 & 16 \\
$\mathrm{U}\left[\mathrm{W} / m^{2} \cdot \mathrm{K}\right]$ & 317,24 & 243,45 & 5 \\
$h_{e}\left[\mathrm{~W} / m^{2} \cdot \mathrm{K}\right]$ & 322,07 & 245,39 & 18 \\
\hline
\end{tabular}

Para calcular o coeficiente de convecção interno, foi utilizada a média aritmética conforme a equação (2). O resultado foi de aproximadamente $300^{\circ} \mathrm{K}$, sendo que as propriedades termofísicas da água com as variações, conforme a temperatura são: $C p_{a g u a}=4.179 \mathrm{~J} / \mathrm{kg} .{ }^{\circ} \mathrm{K} ; \mu=855 \times 10^{-6} \mathrm{~N} . \mathrm{s} / \mathrm{m}^{2} ;{ }^{\circ} \mathrm{K}=0,613 \mathrm{~W} / \mathrm{m} .{ }^{\circ} \mathrm{K} ; \operatorname{Pr}=5,83$.

Todos os cálculos feitos para os casos apresentados foram realizados utilizando o Microsoft Excel, que apresenta entrada e saída de dados conforme a sequência apresentada pelo artigo.

As análises serão feitas através da tabela 3 , que apresenta um resumo dos resultados de todos os casos estudados.

No caso antigo, a temperatura de entrada do óleo nas prensas era elevada, o que ocasionava parada no processo. O trocador de calor estava fornecendo uma taxa de transferência de calor de 30,1 kW, que não estava suprindo a necessidade de troca.

Com intuito de melhorar o sistema de refrigeração, a empresa optou pela utilização de um segundo trocador de calor (caso atual). A taxa de transferência teve um aumento de 16,6\% elevando sua taxa de transferência de calor para $35,1 \mathrm{~kW}$, assim a 
temperatura de entrada do óleo caiu consideravelmente, porém, continuando acima do ideal.

Tabela 3. Resumo dos casos estudados

\begin{tabular}{|c|c|c|c|c|}
\hline Parâmetros & Caso $_{\text {atual }}$ & Caso $_{\text {antigo }}$ & $\begin{array}{c}\text { Caso proposto } \\
\text { novo trocador de calor }\end{array}$ & $\begin{array}{l}\text { Caso proposto aumento } \\
\text { da vazao do caso at ual }\end{array}$ \\
\hline $\mathrm{Te}\left[{ }^{\circ} \mathrm{C}\right]$ & 56 & 65 & 53 & 53 \\
\hline $\mathrm{Q}[\mathrm{W}]$ & 35103,6 & 30088,8 & 40120,41 & 40120,41 \\
\hline $\mathrm{A}\left[\mathrm{m}^{2}\right]$ & 12,18 & 6,09 & 12,88 & 12,18 \\
\hline$\dot{m}_{\text {agua }}[\mathrm{kg} / \mathrm{s}]$ & 1,2 & 1,2 & 1,2 & 1,92 \\
\hline $\mathrm{U}\left[\mathrm{w} / \mathrm{m}^{2} . \mathrm{K}\right]$ & 19,78 & 169,42 & 317,24 & 243,45 \\
\hline $\mathrm{P}[\%]$ & 16,67 & - & 33,34 & 33,34 \\
\hline
\end{tabular}

Ao fazer uma análise sobre o trocador, foram levantadas duas propostas para solucionar o problema.

O primeiro caso faz um estudo sobre a possibilidade de aquisição de um novo trocador de calor, com uma área total de troca térmica capaz de suprir a necessidade da transferência de calor do sistema. Para proporcionar a mesma taxa de transferência de calor do caso anterior de 40,1 kW, o ideal é que o óleo não ultrapasse a temperatura média de $53{ }^{\circ} \mathrm{C}$, neste caso, a área total de troca de calor encontrada foi de 12,38 $m^{2}$. O coeficiente global de transferência de calor encontra-se com o valor de 317,24 $\mathrm{W} / \mathrm{m}^{2} . \mathrm{K}$, o que é possível.

O segundo caso proposto faz uma análise para o caso atual (utilizando dois trocadores de calor), porém, alterando a vazão de $1,2 \mathrm{~kg} / \mathrm{s}$ para $1,92 \mathrm{~kg} / \mathrm{s}$. Para o caso considerado, a taxa de transferência de calor é 40.120,41 W, aproximadamente o dobro de troca que tem com a vazão atual. O coeficiente global de troca térmica ficou com 243,45 W/ $/ m^{2} . \mathrm{K}$, considerado dentro do esperado.

Assim, os dois casos tornam-se viáveis para a solução do problema apresentado. Para se definir o caso mais adequado, é necessário fazer uma análise mais detalhada sobre o custo e o orçamento dos dois casos propostos.

O orçamento de um trocador de calor novo foi fornecido pela própria empresa em que foi realizado o estudo.

Nesse orçamento, está contido o trocador de calor, as mangueiras e guarnição em 
um valor de $\mathrm{R} \$ 3 \cdot 645,80$. Foi levado em consideração também o tempo em que a máquina vai ficar parada para colocar esse trocador de calor na prensa, neste caso a parada é de 60 minutos. O formato mais usual na prensa é o $45 \times 90 \mathrm{~cm}$, o ciclo de prensagem é de oito peças por minuto e o preço médio de custo por metro quadrado para a empresa é de $\mathrm{R} \$ 2,58$. Aplicando a equação 22, temos que o custo total de parada é de $\mathrm{R} \$ 548,60$. Assim, o custo total para o orçamento de um novo trocador de calor é de $\mathrm{R} \$ 4.194,40$.

O orçamento da bomba auxiliar para aumentar a vazão da bomba para 1,92kg/s como estudado acima, foi dado pela empresa Friodinal. Nesse orçamento, está contida uma Bomba BSR 35 Trifásica, encanamentos e componentes elétricos no valor de $\mathrm{R} \$ 1.800,00$. Não é necessária a parada do processo para a instalação dessa bomba auxiliar.

Os custos mensais da bomba centrífuga principal e auxiliar podem ser calculados através da equação 23 a qual aponta que o custo de consumo de energia da bomba nova é de $\mathrm{R} \$ 257,82$ e da bomba atual $\mathrm{R} \$ 2.148,48$.

Com o tempo, nas paredes do trocador de calor vão se formando incrustações dentro e por fora dos tubos. Essas incrustações vão significar uma resistência térmica adicional à troca de calor. Não se pode prever a natureza das incrustações e nem a sua velocidade de formação. Portanto, o fator fuligem só pode ser obtido por meio de testes experimentais em condições reais. No caso atual, na prática, o trocador de calor está sendo parado duas vezes por mês para limpeza, diminuindo sua incrustação e aumentando sua eficiência. Na teoria, com o aumento da vazão, a incrustação diminui, e a parada para a limpeza demora mais para acontecer.

Definindo que o número de paradas para limpeza do trocador de calor para a nova vazão, passa a ser de duas para quatro vezes por mês, pode-se fazer um estudo nos custos como apresentado a seguir.

A tabela 4 apresenta o levantamento de custo para os dois casos propostos apresentados; trocador novo com a nova área, tendo uma parada para limpeza a cada dois meses, e o atual, tendo a vazão alterada com o custo de energia da nova bomba e uma parada para limpeza a cada quatro meses. Esses são os custos que a empresa vai ter com cada um deles por mês. O custo da parada para limpeza do trocador de calor é 
dado pela equação 22, sendo que o tempo de parada para limpeza é de 50 minutos. O formato considerado é o mais usual $45 \times 90 \mathrm{~cm}$, o ciclo de prensagem é de oito batidas por minutos, e o valor encontrado é de $\mathrm{R} \$ 417,00$ por parada.

Tabela 4. Levantamento de custo para os dois casos propostos

\begin{tabular}{lcc}
\hline & Trocador novo [R\$] & Trocador atual com a vazão alterada [R\$] \\
\hline 1 mês & 0 & 257,82 \\
3 meses & 417 & 773,45 \\
6 meses & 1253,88 & 1964,86 \\
9 meses & 1671,84 & 3156,28 \\
12 meses & 2507,76 & 4347,69 \\
24 meses & 5015,52 & 8695,38 \\
36 meses & 7523,28 & 13043,07 \\
\hline
\end{tabular}

Os dois casos propostos resolvem o problema de transferência térmica, com uma análise nos custos, sendo que o trocador de calor novo com a área total de troca térmica correta para o sistema de refrigeração apresentou, mesmo com um valor orçado inicial mais elevado, a opção mais econômica. A escolha por esse novo trocador traz uma economia de até R $\$ 1.840,00$ por ano, ou seja, uma economia de 42,32\% nesse processo.

\section{Conclusões}

A fim de solucionar o problema de transferência de calor no sistema de refrigeração, a opção tomada pela empresa foi a utilização de um segundo trocador de calor que não resolveu o problema, obrigando-a a buscar uma nova opção para solucionálo. Foram estudados os resultados de dois casos propostos, e feito a análise da taxa de transferência que ocorria quando era apenas um trocador de calor, e a transferência de calor que está ocorrendo hoje.

No caso antigo, quando havia somente um trocador de calor, a taxa de transferência de calor média encontrada foi de $30,1 \mathrm{~kW}$, o que se considera baixa para uma transferência eficiente no sistema de refrigeração.

O caso atual, que utiliza um segundo trocador de calor, apresentou uma melhoria no sistema de refrigeração, elevando sua taxa de transferência de calor para 35.103,60 
W, porém, o sistema de refrigeração continuou ineficaz.

O primeiro caso proposto estudou a possibilidade de a empresa em adquirir um trocador de calor novo, com uma área de troca térmica total para suprir a taxa de transferência de calor necessária para a eficiência do sistema de refrigeração. Este caso apresentou uma área de transferência de calor $12,88 \mathrm{~m}^{2}$ para conseguir a eficiência do sistema de refrigeração, sendo que sua aplicação mostrou ser possível.

O segundo caso proposto fez um estudo em cima do caso atual, alterando somente a vazão para $1,92 \mathrm{~kg} / \mathrm{s}$, conseguindo, assim, a transferência para tornar o sistema de refrigeração eficaz. Este caso, assim como o anterior, mostrou que sua aplicação é possível para resolver o problema.

Sendo assim, os dois casos propostos mostraram que suas aplicações resolvem o problema do sistema de refrigeração. Para saber qual a melhor opção a ser tomada pela empresa foram feitas análises econômicas que mostram que a escolha pelo novo trocador de calor será a melhor por proporcionar uma economia de 42,32\% no sistema de refrigeração. Isto se deve à energia elétrica gasta pela bomba auxiliar que aumenta a vazão.

Para trabalhos futuros, podem-se sugerir estudos que tenham em vista melhorar a transferência aumentando a eficiência e alterando o material utilizado na construção do trocador de calor, ou alterando os coeficientes de condutibilidade térmica dos fluidos em evidência.

\section{Referências}

[1] AZEVEDO, N.; MARTINIANO, J.; ALVEREZ, G. Manual de Hidráulica. Edgard Blucher, $8^{a}$ ed., São Paulo, 1998.

[2] SWALTERS, J.; VAN TYNE, C. J. Tecnologia Térmica. 2010. Disponível em: http://www.sfeditora.com.br/tecnologiatermica/publicacoes.aspx?tipo=artigo codigo $=47$. Acesso em mar $/ 2011$.

[3] BRISTOT, V. M. Ferramental para prensagem hidráulica de esferóides de alumina. Dissertação de Mestrado. Universidade Federal do Rio Grande do Sul. Porto Alegre, 2008. 
[4] KREITH, F., BOHN, M. S. Princípios de transferência de calor. São Paulo: SP, 2001.

[5] INCROPERA, F. P.; DEWITT, D. P.; BERGMAN, T. L.; LAYINE A. S. Fundamentos de Transferência de Calor e de Massa. $6^{a}$ ed. Rio de Janeiro, RJ, 2007.

[6] ROSA, R. B. Análise da viabilidade da substituição dos tubos de um trocador de calor casco e tubos de vidro por carbeto de silício. Trabalho de Conclusão de Graduação, Universidade Federal do Rio Grande do Sul, 2009. Disponível em: http://hdl.handle.net/10183/24029.

[7] BALBUENO, G. B. Modelagem hierárquica de trocadores de casco e tubos. Dissertação de Mestrado. Universidade Federal do Rio Grande do Sul. Porto Alegre, RS, 2006.

[8] WELTY, J. R.; WICKS, C. E.; WILSON, R. E.; RORRER, G. L. Fundamentals of momentum, heat, and mass transfer. $2^{a}$ ed, 2007.

[9] BOWMAN, R. A.; MUELLER, A. C.; NAGLE, W. M. Mean temperature difference in design. Transactions of the ASME, v. 62, 1940.

[10] TROCALOR Permutadores de calor Standard modelo bem. Informações Técnicas. Disponível em: http:/www.trocalor.com.br/pdf/cascotubo-rev4-2.pdf 